\title{
Female Status Predicts Female Mate Preferences Across Nonindustrial Societies
}

\section{Fhionna R. Moore Clare Cassidy University of St. Andrews, United Kingdom}

Most studies demonstrating the contribution of economic constraints on women to sex differences in mate preferences have used samples from postindustrial societies with similar social structures. The authors investigate the effects of female status on female mate preferences in a subsection of the Standard Cross-Cultural Sample. Whyte's (1978) codes provide indicators of female status, and mate preferences are obtained through qualitative analysis of ethnographic data in the Human Relations Area Files. Two measures of female status are found to relate to the relative importance of physical appearance to access to resources in attraction to a partner: Domestic authority is associated with greater importance placed on appearance relative to resources, whereas ritualized female solidarity is associated with lower importance of appearance relative to resources. Results are discussed in the context of the contribution of social and economic constraints on women to sex differences.

Keywords: sex differences; mate preferences; female status; nonindustrial societies 
There is considerable evidence for sex differences in human mate preferences. Women have stronger preferences for resources in a partner than do men, whereas men have stronger preferences for physical attractiveness than do women (e.g., Buss, 1989a, 1990, 1994; Buss \& Barnes, 1986; Feingold, 1990, 1991, 1992; GilBurmann, Peláez, \& Sánchez, 2002; Li, Kenrick, \& Bailey, 2002; Waynforth \& Dunbar, 1995). Women prefer partners older than themselves, whereas men prefer partners younger than themselves (e.g., Buss, 1989a; Kenrick \& Keefe, 1992; Otta, da Silva Queiroz, de Sousa Campos, \& Silveira, 1999; Waynforth \& Dunbar, 1995). These sex differences have typically been attributed to sex-specific reproductive constraints (e.g., Buss, 1989a; Kenrick \& Keefe, 1992). Minimal investment in reproduction is higher for females than for males because of the costs of producing large gametes (Bateman, 1948), internal gestation, lactation, and extended parental care (Trivers, 1972). Female reproductive success is therefore constrained by access to the resources necessary to raise costly offspring, whereas male reproductive success is constrained by access to fertile females (Trivers, 1972). Consequently, females should benefit from selecting partners who are able to provide the resources necessary to raise offspring (e.g., older partners who have had time to accumulate resources). Males should benefit from seeking partners demonstrating cues to reproductive capacity and fertility (e.g., a youthful, attractive appearance).

Alternatively, sex differences in mate preferences could arise from sex-specific economic constraints. As women have historically suffered greater constraints to their ability to provide for themselves independently than men, they may have had to seek a partner with the resources required to raise costly offspring, at the cost of preferences for other partner characteristics such as physical attractiveness (e.g., Hrdy, 1997). If this were the case, women's mate preferences should vary with female status: When women have high status, they may be expected to demonstrate less female-typical mate preferences. Positive relationships, however, have been reported between female wealth and preferences for resources in a partner (Buss, 1989b; Gil-Burmann et al., 2002; Townsend, 1989; Wiederman \& Allgeier, 1992). Conversely, attitudes associated with female autonomy (Johannesen-Schmidt \& Eagly, 2002; Koyama, McGain, \& Hill, 2004), cultural levels of female empowerment (Eagly \& Wood, 1999; Kasser \& Sharma, 1999), and control of the resources necessary to raise offspring (Moore, Cassidy, Law Smith, \& Perrett, 2006) are associated with decreased preferences for 
resources and increased preferences for physical attractiveness. Gangestad and Simpson (2000) proposed that these discrepancies reflect differences in measures of status. Wealth may not be the same as the power and control tapped by measurement of female attitudes, empowerment, or resource control. Relationships between wealth and partner preferences may also be confounded by positive assortative mating on the basis of socioeconomic status: Wealthy women may seek partners with similar levels of wealth or background socioeconomic status (Eagly \& Wood, 1999).

The growing evidence for female status relating to more maletypical mate preferences implicates a contribution of economic and social constraints on women to sex differences in preferences. The vast majority of mate preference studies, however, have used samples taken from within Western postindustrial societies (e.g., Johannessen-Schmidt \& Eagly, 2002; Koyama et al., 2004; Moore et al., 2006). Even cross-cultural analyses (e.g., Eagly \& Wood, 1999; Kasser \& Sharma, 1999) have been based on a sample (Buss, 1989a) criticized for overrepresentation of Western societies with cash economies and European influence (Borgia, 1989) and for underrepresentation of traditional societies (Crawford, 1989). In light of these criticisms, it is possible that the effects of female status on sex-differentiated mate preferences are limited to postindustrial societies, arising from conditions particular to a single social structure. The aim of the current study, therefore, was to investigate relationships between female status and mate preferences in traditional, nonindustrial societies with social structures that differ from those used in previous mate preference studies. We predicted that women in societies with higher female status would demonstrate lower preferences for resources and higher preferences for physical attractiveness in a partner than women in societies with lower female status. Additionally, we addressed the criticism of mate preference studies relating to its reliance on self-report data (e.g., Laland \& Brown, 2002) by using qualitative data from ethnographic records.

\section{METHOD}

\section{FEMALE STATUS}

The Standard Cross-Cultural Sample (SCCS; Murdock \& White, 1969) consists of precoded ethnographic data for 186 geographically 
TABLE 1

Codes Dealing With the Status of Women in the Standard Cross-Cultural Sample

\begin{tabular}{ll}
\hline \hline Female Status Code & \multicolumn{1}{c}{ Description of Variable } \\
\hline Property Control Scale & 1 = Women have low control over property \\
& $4=$ Women have high control over property \\
& $1=$ Low power of women in kinship contexts \\
Kin Power Scale & $3=$ High power of women in kinship contexts \\
& $1=$ low value placed on women's lives \\
Value of Life Scale & $3=$ High value placed on women's lives \\
& $1=$ Low value of women's labour \\
Value of Labor & $5=$ High value of women's labour \\
& $1=$ Low women's domestic authority \\
Domestic Authority Scale & $4=$ High women's domestic authority \\
& $1=$ Low female solidarity \\
Ritualised Female & $5=$ High female solidarity \\
Solidarity Scale & $1=$ stricter controls over women's \\
Control of Sex Scale & than men's marital and sexual lives \\
& $3=$ more equal controls over women's and \\
& men's marital and sexual lives \\
Ritualized Fear Scale & $1=$ High ritualized fear of women \\
Joint Participation Scale & $3=$ Low ritualized fear of women \\
& $1=$ Low joint participation of men and women \\
& $3=$ High joint participation of men and women
\end{tabular}

SOURCE: Whyte, 1978.

representative, nonindustrial societies studied by a qualified ethnographic researcher. The societies were selected to be culturally dissimilar to avoid the confounding effects of cultural diffusion and shared histories on cross-cultural analysis (Murdock \& White, 1969). Whyte (1978) conducted an analysis of the status of women in the odd-numbered half sample of the SCCS ( $n=93$ societies) using precoded variables. Measures of female status did not covary such that they could be usefully combined to provide a single variable (Whyte, 1978, 1979). From 52 relevant variables, 9 composite codes of female status were developed (see Table 1). The distributions of males and females on these scales have been replicated in other similar measures (e.g., Hayden, Deal, Cannon, \& Casey, 1986; Hendrix, 1994; Ross, 1986; Sanday, 1981), lending validity to their applicability as a measure of female status. 


\section{MATE PREFERENCES}

Data on the traits considered attractive in males were taken from the Human Relations Area Files (HRAF) for the 17 societies for which data were available (i.e., Alorese, Amhara, Andamanese, Aranda, Bemba, Callinago, Chukchee, Garo, Iban, Inca, Kurd, Mbuti, Pomo, Saramacca, Tupinamba, Wolof, and Yanomamo). The HRAF are a multicultural database, consisting of in-depth ethnographic information taken from a variety of source documents (e.g., books, articles, and dissertations). Relevant predefined codes (i.e., 581: basis of marriage; 832: sexual stimulation), and search terms (i.e., attraction, attractiveness, attracted, beauty, beautiful, mate, and spouse) were identified and used to search for references to female mate preferences in the electronic ethnographic and archaeological databases. Sixty-nine traits were identified.

To develop measures of preferences for male access to resources and physical attractiveness across societies, we computed the sum of references to each. This provided a measure of the number of times these constructs were referred to in the available material for each society and was taken as a proxy of the importance of status and appearance in female mate preferences. Preference for male access to resources was represented as the sum of references to resources and their acquisition as well as general status: industrious, rich, status of family, old (as an indirect measure of accumulated resources), not descended from slaves, property, courage, and hunting ability. The composite score for preferences for physical attractiveness was computed as the sum of references to physical attributes: wavy hair, muscular strength, thick hair, facial hair, square shoulders, wide straight chest, physical attractiveness, light skin, small eyes, medium-sized ear, long face, red facial skin, plump face, wide-apart eyes, heavy eyebrows, straight eyebrows, straight nose, black hair, and bowlegged. A number of physical characteristics were referred to as indicators of status (i.e., large forehead as an omen of good fortune and high bridged nose and thin lips as indicators of nobility) and as such were not included in the composite scores. There were no references to mate preferences for the Callinago, reducing the number of societies in the sample to 16 . The codings of mate preferences from the ethnographic material and development of the composite scores were conducted by two independent researchers. Interrater reliability 
was high (Cronbach's alpha $=.84$ ), and discrepancies in codings were investigated and corrected. A measure of the relative importance of appearance to status in female mate preferences for each society was computed as the number of references to access to resources subtracted from the number of references to physical appearance.

\section{ANALYSIS}

The score representing the relative importance of appearance to status was entered as the dependent variable in a multiple linear regression model, with all female status variables entered as independent variables. This enabled assessment of the effects of each measure of female status on mate preferences. Measures of female status and mate preference generated coefficients within the specified parameters of normality (i.e., skewness coefficients $<+/-1$ or kurtosis coefficients $<+/-3$; West, Finch, \& Curran, 1995).

\section{RESULTS}

The following independent variables showed low tolerance to multicollinearity (i.e., tolerance < 0.4) and were removed: kin power scale, ritualized fear scale, and joint participation scale. Thus, female status scales (i.e., independent variables) in the reduced model were as follows: property control, value of life, value of labor, domestic authority, joint participation, ritualized female solidarity, and control of sex (all tolerance to multicollinearity $>0.4$ ).

Preference for male appearance relative to access to resources was significantly predicted across societies by two measures of female status: domestic authority and ritualized female solidarity (see Table 2). In societies with high female domestic authority, female preferences for a partner's appearance relative to those for status were higher than in those societies with low female domestic authority. Conversely, in societies with high ritualized female solidarity, female preferences for a partner's appearance were relatively lower than those for status. 
TABLE 2

Significant Results of Reduced Model Multiple Linear

Regression ( $n=16$ societies)

\begin{tabular}{lcc}
\hline \hline Female Status Variable & $\beta$ & Significance \\
\hline Domestic authority & 1.02 & 0.02 \\
Ritualized female solidarity & -0.8 & 0.05 \\
\hline
\end{tabular}

NOTE: This table shows the effects of female status on the preference for physical attractiveness relative to access to resources in a partner

\section{DISCUSSION}

The aim of the current study was to investigate the effects of female status on female mate preferences in nonindustrial societies. Predictions were tested in a subsection of the oddnumbered half sample of the SCCS, supplemented with data on mate preferences from the HRAF. We tested the prediction that female status would relate positively to preferences for physical attractiveness over preferences for resources in a partner, across societies. Using Whyte's (1978) codes on the status of women, conflicting results were found, suggesting complexity in the construct female status.

In societies with high female domestic authority, women had relatively stronger preferences for physical attractiveness than status in a partner than in those with lower female domestic authority. In societies with high ritualized female solidarity, however, women had relatively lower preferences for a partner's appearance relative to status than in those with lower female solidarity.

Although the former result supports the prediction that women in societies with higher female status will express more maletypical mate preferences, the latter suggests that women in societies with higher female status express stronger female-typical mate preferences. It is possible that only specific aspects of the complex female status construct lead to more male-typical female mate preferences. The domestic authority scale is composed of items assessing whether there is an explicit view that men should dominate their wives as well as who has final authority over the upbringing of infants and postinfant unmarried children. The ritualized female 
solidarity scale is composed of items that assess the prevalence of community-wide exclusively male or female work groups, menstrual taboos, existence of female initiation ceremonies, and the existence of a clearly stated belief that women are inferior to men. Although both scales appear to tap the general status of women, the domestic authority scale may assess the status of women within marriage, whereas the female solidarity scale may tap more general attitudes toward women. As both scales provide a measure of the status of women, it is not possible to conclude that greater female status leads to expression of male-typical mate preferences. The results do, however, provide interesting insight into the importance of aspects of female status in determining mate preferences. It is possible that it is power and status of women in the home that enables women to adjust their mate preferences.

By using the SCCS, we investigated the effects of female status on mate preferences in societies that differ considerably from those used in previous studies. This has facilitated a more comprehensive assessment of the role of constraints on women in sexdifferentiated preferences. Furthermore, the use of ethnographic data has provided an alternative method to the widely used questionnaire responses of undergraduate students. Previous studies have relied on preference rankings for specific partner characteristics such as physical attractiveness and good financial prospects. It was necessary in this study to use references to less specific partner characteristics related to a partner's physical appearance and resource acquisition and status. Results of the current analysis demonstrate that relationships between female status and partner preferences hold across nonindustrial societies and different measures of female status and mate preferences.

Female domestic authority was associated with female mate preferences more like those typical of males across a sample of nonindustrial societies, providing further evidence for the contribution of social and economic constraints on women to sex differences in mate preferences. When women are not dominated by their husbands and therefore have greater equality in terms of power in the household, they express more male-typical mate preferences. Although the results demonstrate complexity in the construct female status, they also show some consistency with the effects of female status on preferences in postindustrial societies, suggesting that the effects of female status found in previous studies do not appear to arise from conditions unique to postindustrial societies. 
The results also provide insight into the aspects of female status that may enable women to adjust their mate preferences.

\section{References}

Bateman, A. J. (1948). Intra-sexual selection in Drosophila. Heredity, 2, 349-368.

Borgia, G. (1989). Typology and mating preferences. Behavioral and Brain Sciences, 12, 16-17.

Buss, D. M. (1989a). Sex differences in human mate preferences: Evolutionary hypotheses tested in 37 cultures. Behavioral and Brain Sciences, 12, 1-49.

Buss, D. M. (1989b). Toward an evolutionary psychology of human mating. Behavioral and Brain Sciences, 12, 39-49.

Buss, D. M. (1990). International preferences in selecting mates: a study of 37 cultures. Journal of Cross-cultural Psychology, 21, 5-47.

Buss, D. M. (1994). The evolution of desire: Strategies of human mating. New York: Basic Books.

Buss, D. M., \& Barnes, M. (1986). Preferences in human mate selection. Journal of Personality and Social Psychology, 50, 559-570.

Crawford, C. (1989). Sex differences in life histories: The role of sexual selection and mate choice. Behavioral and Brain Sciences, 12, 18.

Eagly, A. H., \& Wood, W. (1999). The origins of sex differences in human behavior: Evolved dispositions versus social roles. American Psychologist, $54,408-423$.

Feingold, A. (1990). Gender differences in effects of physical attractiveness on romantic attraction-A comparison across 5 research paradigms. Journal of Personality and Social Psychology, 59, 981-993.

Feingold, A. (1991). Sex-differences in the effects of similarity and physical attractiveness on opposite- sex attraction. Basic Applications of Social Psychology, 12, 357-367.

Feingold, A. (1992). Gender differences in mate selection preferencesA test of the parental investment model. Psychological Bulletin, 112, 125-139.

Gangestad, S. W., \& Simpson, A. S. (2000). The evolution of human mating: Trade-offs and strategic pluralism. Behavioral and Brain Sciences, 23, 573-587.

Gil-Burmann, C., Peláez, F., \& Sánchez, S. (2002). Mate choice differences according to sex and age: An analysis of personal advertisements in Spanish newspapers. Human Nature, 13, 493-508.

Hayden, B., Deal, M., Cannon, A., \& Casey, J. (1986). Ecological determinants of women's status among hunter/gatherers. Human Evolution, 1, 449-473.

Hendrix, L. (1994). What is sexual inequality? On the definition and range of variation. Cross-Cultural Research, 28, 287-307.

Hrdy, S. B. (1997). Raising Darwin's consciousness: Female sexuality and the prehominid origins of patriarchy. Human Nature, 8, 1-49. 
Johannesen-Schmidt, M. C., \& Eagly, A. H. (2002). Another look at sex differences in preferred mate characteristics: the effects of endorsing the traditional female gender role. Psychology of Women Quarterly, 26, 322-328.

Kasser, T., \& Sharma, Y. S. (1999). Reproductive Freedom, educational equality, and females' preference for resource-acquisition characteristics in mates. Psychological Science, 10, 374-377.

Kenrick, D. T., \& Keefe, R. C. (1992). Age preferences in mates reflect sex differences in human reproductive strategies. Behavioral and Brain Sciences, 15, 75-133.

Koyama, N. F., McGain, A., \& Hill, R. A. (2004). Self-reported mate preferences and "feminist" attitudes regarding marital relations. Evolution and Human Behavior, 25, 327-335.

Laland, K. N., \& Brown, G. R. (2002). Sense and nonsense: Evolutionary perspectives on human behaviour. Oxford, UK: Oxford University Press.

Li, N. P., Kenrick, D. T., \& Bailey, M. (2002). The necessities and luxuries of mate preferences: Testing the tradeoffs. Journal of Personality and Social Psychology, 82, 947-955.

Moore, F. R., Cassidy, C., Law Smith, M. J., \& Perrett, D. I. (2006). The effects of female control of resources on sex differentiated mate preferences. Evolution and Human Behavior, 27, 193-205.

Murdock, G. P., \& White, D. R. (1969). Standard cross-cultural sample. Ethnology, 8, 329-369.

Otta, E., da Silva Queiroz, R., de Sousa Campos, L., \& Silveira, M. T. (1999). Age differences between spouses in a Brazilian marriage sample. Evolution and Human Behavior, 20, 99-103.

Ross, M. (1986). Female political participation: A cross- cultural explanation. American Anthropologist, 88, 842-858.

Sanday, P. R. (1981). Female power and male dominance: On the origins of sexual inequality. New York: Cambridge University Press.

Townsend, J. M. (1989). Mate selection criteria: A pilot study. Ethology and Sociobiology, 10, 241-253.

Trivers, R. L. (1972). Parental investment and sexual selection. In B. Campbell (Ed.), Sexual selection and the descent of man (pp. 136179). Hawthorne, NY: Aldine.

Waynforth, D., \& Dunbar, R. I. M. (1995). Conditional mate choice strategies in humans: Evidence from 'Lonely Hearts' advertisements. Behaviour, 132, 755-779.

West, F. G., Finch, J. F., \& Curran, P. J. (1995). Structural equation models with nonnormal variables: Problems and remedies. In R. H. Hoyle (Ed.), Structural equation modelling: Concepts, issues and applications (pp. 56-75). Thousand Oaks, CA: Sage.

Whyte, M. K. (1978). Cross-cultural codes dealing with the relative status of women. Ethology, 17, 211-237.

Whyte, M. K. (1979). The status of women in pre-industrial society. Princeton, NJ: Princeton University Press.

Wiederman, M. W., \& Allgeier, E. R. (1992). Gender differences in mate selection criteria: Sociobiological or socio-economic explanation? Ethology and Sociobiology, 13, 115-124. 
Fhionna Moore is a PhD student in psychology at the University of St. Andrews, United Kingdom. Her research interests include the effects of female status on mate preferences and reproductive strategies and facial attractiveness

Clare Cassidy is a lecturer in psychology at the University of St. Andrews, United Kingdom. She received her PhD in psychology from The Queen's University of Belfast, United Kingdom, and her research interests include gender identity, group processes, and health. 